\title{
Innervation of the Anterior Spinal Canal: An Update
}

\author{
Russell V. Gilchrist, DO*, Zacharia Isaac, MD*, and Atul L. Bhat, MD*
}

Understanding the innervation of the lumbar spine can be a daunting task. Until recently, only macroscopic visualization and crude histological techniques were available to document the presence of nerve fibers in the anterior spinal canal. Using newer immunohistochemical techniques, studies have been able to more thoroughly investigate the innervation of the anterior spinal canal. The presence of sensory nerve fibers has been definitively identified in all anterior spinal structures. These sensory fibers enable any of the spinal structures the capability of being a pain generator. These sensory nerve fibers tend to form dense interwoven plexuses on the posterior longitudinal ligament and ventral surface of the dura mater. The plexuses allow for anastamoses to take place between nerve fibers from multiple segmental levels. This polysegmental formation causes the expression of low back pain to be diffuse, rather than focal. It is these diffuse pain symptoms that create great difficulty in diagnosing and treating spinal canal structures.

Key words: Back pain, innervation, immunohistochemistry, posterior longitudinal ligament, intervertebral disc.
There has been a plethora of research dedicated to establishing the presence of nociceptive nerve fibers within the annulus fibrosus and posterior longitudinal ligament. Absence of these fibers would negate the disc from being responsible as a pain generating structure within the lumbar spine. Luschka was the first to describe the presence of a nerve re-entering the intervertebral foramen and terminating in the substance of the posterior longitudinal ligament and annulus fibrosus of the intervertebral disc (1). This nerve became known as the recurrent nerve of Luschka, and today we refer to it, as the sinuvertebral nerve. Later studies by numerous authors in the early $20^{\text {th }}$ century confirmed Luschka's findings and established that this nerve provided primary innervation to all structures within the spinal canal (2-6).

In an elegant and meticulous anatomic study, Bogduk et al (7) also demonstrated the course of the sinuvertebral nerve using microscopic analysis, it was revealed the sinuvertebral nerve entered the spinal canal through the intervertebral foramen by passing just inferior to the pedicle. Once in the canal, the nerve traveled superiorly along the edge of the

From the Department of Rehabilitation Medicine, University of Pennsylvania, Philadelphia, Pennsylvania. *Fellows at the Penn Spine Center. Address correspondence: Russell V. Gilchrist, DO, 3400 Spruce Street, Ground Floor - Whyte Building, Philadelphia, PA 19104.

E-mail:Russellss11@msn.com posterior longitudinal ligament (7). During this course, multiple branches are given to the posterior longitudinal ligament. A multitude of smaller branches from the sinuvertebral nerve were identified descending from the intervertebral foramen to terminate at the intervertebral disc level of the parent ventral rami (7). Other authors have reported noting the sinuvertebral nerve existing as a number of small filaments outside the intervertebral foramen (8 -10). Up to six filaments have been noted by Edgar et al (10). These filaments were not found to merge as they entered the intervertebral foramen, and the largest filament was noted to follow the typical course described above by Bogduk.

The ascending and descending branches of the sinuvertebral nerve combine to form a plexus on the posterior longitudinal ligament $(12,13)$. This plexus is most likely formed by anastamoses with branches from the sinuvertebral nerve on the opposite side and with those from superior and inferior adjacent levels (14). There is still controversy in the literature regarding regarding how far these ascending and descending branches may travel prior to anastamoses with neighboring branches. Spurling and Bradford et al (3) noted the descending branches passing two segments below their level of entry into the canal. One early study theorized that ascending branches ran along the whole length of the spinal column, thereby forming anastamoses at all levels (15). Other earlier studies were unable to find any evidence of anastamoses between branches of the sinuvertebral nerve $(9,16)$. They theorized that each sinuvertebral nerve was purely segmental in its innervation. Bogduk et al and others have demonstrated 
anastamoses of ascending branches one level cephalad of their entry point $(7,17)$. It is generally agreed that anastamoses do exist between ascending and descending branches of the sinuvertebral verve. The level of anastamoses still is in question, but prevailing data would suggest that it occurs one to two adjacent levels above and below its level of entry into the spinal canal $(7,17)$.

Thick meningeal branches from the sinuvertebral nerve, thin branches from the nerve plexus of the dorsal posterior ligament, and small branches of perivascular nerve plexuses of the radicular rami of segmental arteries all coalesce to form an anterior nerve plexus on the ventral aspect of the dura mater $(10,18,19)$. Stilwell et al (20) was one of the first studies to demonstrate evidence of meningeal branches penetrating the ventral spinal dura in monkeys (20). Three years later, Bridge et al (21) discovered epidural nerves terminating on the dural surface of the cat, dog, and man. In 1961, Kimmel et al (18) documented the presence of meningeal branches from the sinuvertebral nerve penetrating the spinal dura. Using the process of acetylcholinesterase histochemistry, Groen et al (22) was able to demonstrate the presence of a dense plexus of nerve fibers on the ventral dura of the human fetus. A majority of these ventral fibers were thought to be autonomic in origin. Ahmed et al (23) corroborated Groen's findings of autonomic fibers on the ventral dural surface. More recent immunohistochemical studies have also demonstrated the presence of sensory afferent fibers lining the ventral dural plexus $(19,23)$.

The nerve branches of the posterior ligament plexus also form the primary innervation of the posterior longitudinal ligament and postero-lateral aspect of the intervertebral disc. The first studies to report the presence of nerve endings on the intervertebral disc and adjacent posterior longitudinal ligament were published in the early 1930's (24 - 26). They noted nerve fibers in the posterior longitudinal ligament and on the superficial aspect of the identified nerve fibers within the outer annulus in the early 1940's.

In 1959, Malinsky et al (27) demonstrated the presence of non-encapsulated nerve endings in the outer third of the annulus fibrosus, and encapsulated fibers on the surface of the disc. The greatest number of fibers was noted to occur in the lateral region of the disc, with the anterior and posterior regions demonstrating few nerve fibers (27). These findings were later confirmed by Rabischong et al (28) in 1978 and Yoshizawa et al (29) in 1980. In Yoshizawa's study, they demonstrated the presence of an abundant axonal network in the posterior ligament and outer half of the annulus fibrosus, with abundant free-lying terminals, often arranged in complex, branched-spray formations. These free-lying nerve fibers were primarily found in the lateral aspect of the disc, and had similar morphology to pain receptors reported elsewhere (30). Histological studies by Bogduk also supported Malinsky's findings, where he noted nerve fibers up to a depth of one-third the total thickness of the annulus fibrosus (7). Bogduk has also reported additional nervous innervation of the disc through pathways other than direct branches from the sinuvertebral nerve. These included direct branches from the ventral rami, and two types of branches from the rami communicantes. All of these branches enter the posterolateral aspect of the intervertebral disc. Branches from the rami communicantes were also noted to travel caudally and overly the subjacent disc (7).

The advent of immunohistochemical techniques has led to reassessment of spinal neural elements. This reevaluation has offered the added advantage of an enhanced precision in delineating neural structures while simultaneously characterizing neural chemical constituents (31). In other words, this technique will not only identify nerve fibers, but can differentiate these fibers from one another based upon the neural peptides used by each specific nerve type. For instance, a number of neuropeptides are known to occur in afferent nerve fibers. These neuropeptides include substance $\mathrm{P}$, somatostatin, cholecystokininlike substance, vasoactive intestinal polypeptide(VIP), calcitonin gene-related peptide(CGRP), gastrin-releasing peptide, dynorphin, enkaphalin, and galanin (31-33). Substance $\mathrm{P}$, vasoactive intestinal peptide, and calcitonin gene related peptide are believed to be specific sensory transmitters $(33,34)$ and may also be involved in nociceptive transmission (35 - 37), neurogenic inflammation $(38,39)$, and skeletal metabolism. By using specific antibodies to these peptides an afferent sensory fiber may be identified in spinal tissues, whereas primary motor fibers are not.

One of the first reported studies documenting the presence of sensory nerve fibers within the annulus fibrosus was by McCarthy et al (40) in 1991. In their study calcitonin gene related peptide was used as the specific marker for sensory nerve fibers. Using immunohistochemical techniques, they were able to identify immunoreactive sensory fibers within the outer layers of the annulus fibrosus of all discs sampled. These nerve fibers were concentrated at the interfaces of the posterior longitudinal ligament and disc. No immunoreactive fibers were noted in the inner portion of the annulus fibrosis or nucleus pulposus (40). 
More recent immunohistochemical studies in human discs have also demonstrated the presence of sensory nerve fibers in the annulus fibrosus $(41,42)$. Palmgren et al (41) performed histochemical analysis using substance $\mathrm{P}$ and C-flanking peptide of neuropeptide $\mathrm{Y}(\mathrm{CPON})$ as nerve markers for sensory and autonomic nerve fibers, respectively. Synaptophysin(SYN) served as a general neuronal marker for the study. Nine normal nondegenerated lumbar intervertebral disc tissue specimens were stained and underwent microscopic analysis. Substance P immunoreactivity was seen in $50 \%$ of the posterior annulus specimens. CPON reactive fibers were seen in $75 \%$ of the posterior annulus specimens, and SYN fibers were seen in $75 \%$ of posterior annular specimens. Interestingly, all anterior annulus specimens demonstrated the presence of substance $\mathrm{P}$ and CPON fibers. The depth of penetration of immunoreactive fibers was also recorded using a morphometric scale attached to the microscope. A maximum depth of .50mm was seen for substance P, $.45 \mathrm{~mm}$ for CPON, and $3.5 \mathrm{~mm}$ for SYN.

In 1994, Ashton et al (43) performed immunohistochemical analysis of 12 human intervertebral discs. These discs were obtained from patients undergoing anterior lumbar fusion secondary to intractable low back pain. Protein gene product (PGP 9.5) served as a general nerve marker, and CPON as a marker for autonomic fibers. CGRP, VIP, and substance $\mathrm{P}$ acted as primary sensory markers. Immunoreactivity to CGRP, substance P, CPON, and VIP were seen throughout the outer $3 \mathrm{~mm}$ of the annulus fibrosus. No immunoreactive fibers were noted penetrating the deep fibers of the annulus or in the nucleus pulposus. Substance $\mathrm{P}$ fibers were the sparsest fibers seen on microscopic analysis. Only a small number of these fibers were detected in the periphery of the disc. CPON fibers were exclusively noted traveling in association with blood vessels (43).

Only two studies to date have been able to document, via immunohistochemical techniques, the presence of nerve fibers penetrating the inner half of the annulus fibrosus and into the nucleus pulposus $(44,45)$. In both studies disc specimens were taken from patients with chronic low back pain undergoing anterior spinal fusion. All biopsy specimens were taken from the anterior portion of lumbar intervertebral discs. Freemont et al (45) examined 46 intervertebral discs from 38 subjects. Substance P immunoreactive fibers were identified in the inner third of the annulus fibrosus in $46 \%$ of non-control discs in this study (45). Freemont noted an association with blood vessels and nerve fibers penetrating the inner portions of the annulus fibrosus. Coppes et al (44) examined 10 degenerated lumbar discs and two normal (control) discs. He was able to identify only "occasional single immunoreactive nerve fibers" for substance P into the inner third of the annulus. In contrast to Freemont's observations, Coppes study did not note any correlation between ingrowth of blood vessels and nerve tissue into the annulus.

A multitude of animal studies have also documented the presence of nerve fibers in the posterior longitudinal ligament and annulus fibrosus (46 -50). Those studies using immunohistochemical techniques have specifically been able to identify the presence of sensory afferent fibers in the posterior longitudinal ligament and superficial annular fibers $(46,48)$. Similar to most human studies, animal studies have been unable to demonstrate the presence of afferent nerve fibers within the inner aspects of the annulus fibrosus and nucleus pulposus. In 1995,Imai et al (47) was able to demonstrate a dual innervation to the posterior longitudinal ligaments in rats. A superficial network on the dorsal aspect of the posterior longitudinal ligament was seen to contain both nociceptive and sympathetic fibers. This dorsal plexus formed a polysegmental innervating system by anastamoses from adjacent upper and lower fibers. A deeper network ventral to the posterior longitudinal ligament was seen to contain only nociceptive fibers. This deeper network did not form connections with adjacent levels at the level of the intervertebral disc, thereby making this ventral network unisegmental in innervation (45). Another study has also promulgated a possible alternate pathway for return of annular sensory nerve fibers through the sinuvertebral nerve, rami communicants, and the lumbar sympathetic trunks (50). This is in contrast to traditional belief that sensory nerve fibers only traveled afferently through the ventral rami, instead of rami communicants and lumbar sympathetic trunk (51).

Based on current data, it is evident the intervertebral disc has a rich nerve supply in its lateral portion. These nerve fibers cover the superficial aspect of the disc and penetrate the annulus to a minimal extent. Thick networks of nerve fibers innervate the posterior longitudinal ligament. This network probably involves a large amount of crossinnervation between neighboring levels. This complex network would then give each posterior longitudinal ligament a diffuse, poly-segmental innervation. In addition, there may exist poly-segmental pathways in which these fibers may return to the spinal cord. The ventral dura also contains a rich polysegmental innervation of both autonomic and nociceptor fibers. This diffuse innervation to the contents of the anterior spinal canal highlights the 
difficulty of diagnosing the etiology of low back pain. As well, it reminds us that poorly localized low back pain complaints should be common. This redundancy in innervation may explain why the treatment of low back pain patients continues to be one of the greatest challenges to the pain physician today.

\section{PRACTICAL IMPLICATIONS}

- Intervertebral discs contain sensory nerve fibers capable of transmitting pain impulses.

- Diagnosis of a specific pain generator in the spinal canal is troublesome secondary to its diffuse, polysegmental innervation.

- Treatment of anterior canal spinal pain may best be accomplished by ablation of the larger sensory nerve fibers outside the intervertebral foramen.

\section{REFERENCES}

1. Luschka, H. Die Nerven des Menschlichen Wirbelkanales. Tubingen; Laupp, 1850.

2. Hovelacque, A. Anatomie des Nerfs Craniens et Rachidiens et du Systeme Grand Sympathique. Paris; Doin, 1927.

3. Spurling, R.G. Neurologic aspects of herniated nucleus pulposus. JAMA 1939; 113: 2019-2022.

4. Roofe, P.G. innervation of annulus fibrosus and poste rior longitudinal ligament. Archives of neurology and psychiatry 1940; 44: 110-113.

5. Buskirk, C. Nerves in the vertebral canal. Archives of Surgery 1941; 43: 427-432.

6. Spurling RG, Grantham EG. Neurologic picture of the nucleus pulposus in the lower part of the lumbar re gion. Archives of Surgery 1940;40: 378-381.

7. Bogduk N, Tynan W, Wilson AS. The nerve supply to the human lumbar intervertebral discs. J. Anatomy 1981; 132: 39-56.

8. Pederson HE, Blunck CFJ, Gardner E. The anatomy of the lumbosacral posterior rami and meningeal branches of the spinal nerves. J Bone Joint Surg 1956;38A: 377-391

9. Wiberg, G. Back pain in relation to the nerve supply of the intervertebral disc. Acta Orthop Scand 1947; 19: 211-221

10. Edgar MA, Nundy S. Innervation of the spinal dura mater. J Neurol. Neurosurg. Psychiat. 1966; 29: 530534

11. Groen GJ, Baljet B, Drukker J. Nerve and nerve plex uses of human vertebral column. Am J Anat 1990; 188 : 282-296.

12. Mulligan JH. The innervation of the ligaments at tached to the bodies of the vertebrae. J. Anatomy 1957; 91: 455-65.

13. Groen, G.J, Baljet B, Drukker J. The innervation of the spinal dura mater: anatomy and clinical implica tions. Acta Neurochir 1988; 92: 39-46.

14. Edgar MA, Ghadially JA. Innervation of the lumbar spine. Clin Orthop and Related Research 1976; 115: $35-41$.

15. Van Buskirk C. Nerves in the vertebral canal. Their relation to the sympathetic innervation of the upper extremities. Arch Surg 1941; 43: 427.

16. Lazorthes G. Etude sur les nerfs sinu-vertebraux lombaires le nerf de roofe existe-t-il? Compt. Rend assoc. Anat. Reunion 1948; 34: 317-320

17. Pederson ME, Blunck CFJ, Gardner E. The anatomy of the lumbosacral posterior rami and meningeal branches of spinal nerves. J Bone Joint Surg 1956; 38A: 377-391.

18. Kimmel DL. Innervation of the spinal dura mater and dura mater of the posterior cranial fossa. Neurology 1960; 10: 800-809.

19. Kallakuri S, Cavanaugh JM, Blagoev DC. An Immu nohistochemical Study of Innervation of Lumbar spi nal dura and longitudinal ligaments. Spine 1998; 23(4): 403-411.

20. Stilwell, D.L. The nerve supply of the vertebral col umn and its associated structures in the monkey. Anat Rec 1956; 125: 139-153.

21. Bridge, C.J. Inervation of spinal meninges and epidu ral structures. Anat Rec 1959; 166: 533-563.

22. Groen GJ, Baljet B, Drukker J. The innervation of the spinal dura mater. Acta Neurochir (Wien) 1988; 92 : $39-46$.

23. Ahmed M, Bjurholm A, Kreicberg M, et al. Neu ropeptide Y, tyrosine hydroxylase, and VIP fibers in the vertebral bodies, discs, dura mater, and spinal liga ments of the rat lumbar spine. Spine 1993; 18: 268273

24. Jung, A. Recherches histologique des articulations descorps vertebraux. La Presse Medicale 1932; 40: 316-317.

25. Roofe PG. Innervation of annulus fibrosus and poster ior longitudinal ligament: fourth and fifth lumbar level. Arch Neurol. Psychiat. 1940; 44: 100-103

26. Ehrenhaft JL. Development of the vertebral column as related to certain congenital and pathological changes. Surg Gynec Obstet 1943; 76: 282-292.

27. Malinsky J. The ontogenic development of nerve ter 
minations in the intervertebral discs of man. Acta Anat 1959; 38: 96-113.

28. Rabischong P, Louis R, Vignaud J, et al. The interver tebral disc. Anat Clin 1978; 1: 55-64.

29. Yoshizawa H, O'Brien JP, Smith WT, et al. The neuro pathology of intervertebral discs removed for low back pain. J. Pathology 1980; 132: 95-104.

30. Ham AW. Histology. Philadelphia. Churchill Livingstone. 1974: 939.

31. Gronblad M, Weinstein JN, Santavirta S. Immunohis tochemical observations on spinal tissue innervation. Acta Orthop Scand 1991; 62: 614-622.

32. Gibbins IL, Furness JB, Costa M. Pathway-specific patterns of co-existence of substance $\mathrm{P}$, calcitonin gene related peptide, cholecystokinin and dynorphin in neu rons of the dorsal root ganglion of the guinea pig. Cell tissue research 1987; 248: 417-437.

33. Lee Y, Takami K, Kawai Y, et al. Distribution of calci tonin gene related peptide in the rat peripheral nervous system with reference to its coexistence with substance P. Neuroscience 1985; 15: 1227-1237.

34. Hokfelt T, Kellerth JO, Nilsson G, et al. Substance P: localization in the central nervous system and in some primary sensory neurons. Science 1975; 190: 889890.

35. Henry, J.L. Relation of substance P to pain transmis sion: neurophysiological evidence. In: Substance P in the Nervous System. pp. London. Pitman, 1992: 206224

36. Lembeck F, Donnerer J, Colpaert FC. Increase of sub stance $\mathrm{P}$ in primary afferent nerves during chronic pain. Neuropeptides 1981; 1: 175-180.

37. Oku R, Satoh M, Fuji N, et al. Calcitonin gene related peptide promotes mechanical nociception by potenti ating release of substance $\mathrm{P}$ from the spinal dorsal horn in rats. Brain Resear. 1987; 403: 350-354.

38. Lotz M, Carson DA, Vaughan JH. Substance P activa tion of rheumatoid synoviocytes: neural pathway in pathogenesis of arthritis. Science 1987; 235: 893-895.

39. Santavirta S, Gronblad MV, Konttinen YT, et al. Neu ropeptides implicated in pain perception and neuro genic inflammation in joint disease. J Orthop Rheum 1990; 3: 35-44.

40. McCarthy PW, Carruthers B, Martin D, et al Immunohistochamical demonstration of sensory nerve fibers and endings in lumbar intervertebral discs of the rat. Spin 1991; 16(6): 653- 655.

41. Palmgren T, Gronblad M, Virri J, et al. An immunohis tochemical study of nerve structures in theannulus fibrosus of human normal lumbar intervertebral discs. Spine 1999; 24: 2075-2079.

42. Ashton IH, Roberts S, Jaffray DC. Neuropeptides in the human intervertebral disc. J Orhtop Res 1994; 12: 186-192.

43. Moore, K.L. Anatomy. Williams and Wilkins; Balt, Md. 1992; 323-369.

44. Coppes MH, Marani E, Thomeer TWM. Innervation of annulus fibrosus in low back pain (letter). Lancet 1990; 336: 189-190.

45. Freemont AJ, Peacock TE, Goupille P, et al. Nerve ingrowth into diseased intervertebral disc in chronic back pain. Lancet 1997; 360: 178-81.

46. Cavanaugh JM, Kallakuri S, Ozaktay AC. Innervation of rabbit lumbar intervertebral disc and PLL. Spine 1995; 20: 2080-2085

47. Imai S, Hukuda S, Maeda T. Dually Innervating Noci ceptive Networks in the Rat Lumbar Posterior Longi tudinal Ligaments. Spine 1995; 20(19): 2086-2092.

48. Gronblad M, Korkala O, Konttinen YT, et al. Silver impregnation and immunohistochemical study of nerves in the lumbar facet joint plical tissue. Spine 1991; 16: 34-8.

49. Ohtori S, Takahashi K, Chiba T, et al. Sensory innerva tion of the dorsal portion of the lumbar intervertebral discs in rats. Spine 2001; 26: 946-950.

50. Suseki K, Takahashi Y, Takahashi K, et al. Sensory nerve fibers from lumbar intervertebral discs pass through rami communicans. J Bone Joint Surg 1998; 80-B: 737-742.

51. Wiberg G. Back pain in relation to the nerve supply of the intervertebral disc. Acta Orhtop Scand 1947;

19: $211-221$ 